\title{
HOMENAGEM AO PROFESSOR DOUTOR EBERHARD WERNICK In Memoriam (1940 - 2017)
}

O Professor Doutor Eberhard Wernick era natural de Berlim, Alemanha, nascido em 12 de junho de 1940 e nos deixou no dia 29 de dezembro de 2017.

Formou-se em Geologia em 1963, na quarta turma do Curso de Geologia da antiga Faculdade de Filosofia e Letras da Universidade de São Paulo, tendo iniciado sua carreira acadêmica já em 1964 na antiga Faculdade de Filosofia, Ciências e Letras de Rio Claro, hoje UNESP Câmpus de Rio Claro.

Desde cedo adquiriu excelente nome profissional, consolidado em numerosas atividades como pesquisador e professor. Obteve o título de Doutorado em Geociências em 1967 pela Universidade Estadual de Campinas, defendendo a tese intitulada "Geologia da Região de Amparo, leste do Estado de São Paulo” e, em 1969, realizou pós-doutorado pela Christian Albrecht Universität Kiel, Alemanha.

Tornou-se livre-docência em 1972 com a tese versando sobre "Geologia do Maciço Granítico Morungaba, leste do Estado de São Paulo", defendida na antiga Faculdade de Ciências e Letras de Rio Claro, hoje Instituto de Geociências e Ciências Exatas da UNESP. Em 1975, tornou-se Professor Adjunto e em 1980, Professor Titular em Petrologia e Geoquímica no mesmo Instituto, onde se aposentou em 2006. Complementando sua formação, realizou várias atualizações nas áreas de petrologia magmática e geoquímica, especialmente focando rochas granitoides, em instituições na Alemanha (1977, 1982, 1989, 1991).

Durante sua extensa carreira acadêmica, com mais de quatro décadas de atividades de ensino e pesquisa, atou de forma extremamente ativa e reconhecidamente entusiástica no trato das Geociências, especialmente no estudo das rochas granitoides, sua grande especialidade e paixão. Ministrou diversas disciplinas (destacando-se as disciplinas Petrologia Magmática; Geoquímica; Geotectônica; Rochas Granitoides) na graduação e na pós-graduação, além de inúmeros cursos de especialização, ligados à Geologia do IGCE/UNESP e a outros vários de pós-graduação em Geociências por todo

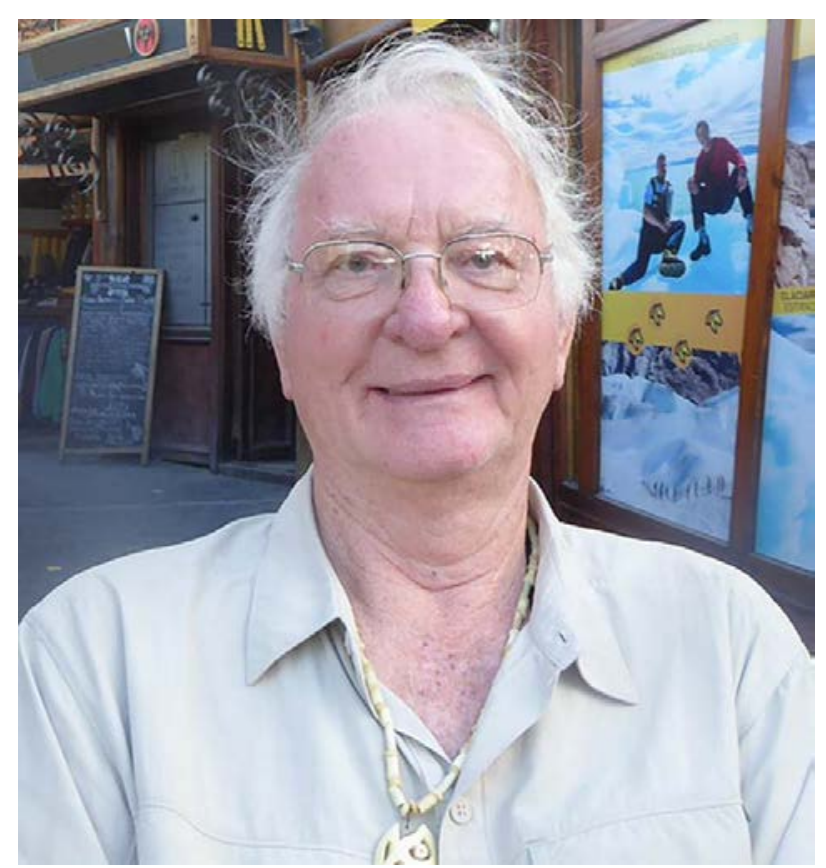

Foto do Prof. Dr. Eberhard Wernick obtida junto ao site https://enegeomg2017.wixsite.com/melhorenegeodetodos ?lightbox=dataItem-izk217hu

o pais. Proferiu também treinamentos, cursos e palestras em instituições de pesquisa e em congressos. Em suas animadas conversas e manifestações, dizia-se apaixonado pelas Geociências e pelas atividades acadêmicas, o que se refletia em suas atividades didáticas, na atenção e no carinho recebido dos alunos que acompanhavam suas disciplinas.

Teve grande importância junto ao desenvolvimento do Curso de Geologia de Rio Claro. Foi um dos fundadores do Curso, ainda na antiga Faculdade de Filosofia, Ciências e Letras de Rio Claro, em 1969, e do Curso de PósGraduação do IGCE/UNESP, tendo exercido a coordenação deste no triênio 1985-1988. Teve destacada participação em atividades e representações de vários Órgãos Colegiados da Universidade, além quatro mandatos de chefia departamental e coordenador Científico do Grupo Acadêmico ROCHAS GRANITÓIDES da UNESP / Rio Claro.

Foi responsável pela instalação e desenvolvimento do Laboratório de "Tipologia de Zircão" e participação na criação dos Laboratórios de "Preparação de Amostras" e de "Geoquímica” da UNESP, os quais contaram 
com apoio financeiro de várias instituições de fomento à pesquisa como FAPESP, CAPES, CNPq, FINEP, FUNDUNESP, DAAD e da Fundação Volkswagen.

$\mathrm{Na}$ sua vida acadêmica coordenou e/ou participou de inúmeros projetos de pesquisa nacionais e internacionais, cabendo, entre outros, destacar: coordenador adjunto do Mapa Geológico do Estado de São Paulo no âmbito do convênio DAEE-SP-PRÓ-MINÉRIO-SP (1983-86); vice-presidente do International Academic Teaching Board, ligado ao desenvolvimento de novas metodologias de ensino avançado (técnicas de motivação e cooperação, sinergia, dinâmica de grupo, psicodrama), entre 1989 e 1995; presidente da Comissão Técnica-Científica GRANITÓIDES e MINERALIZAÇÕES ASSOCIADAS da Sociedade Brasileira de Geologia. Com destaque das atividades de pesquisa internacionais, atuou como: membro da COMISSION ON GRANITES da International Association of Volcanology and Chemistry of the Earth Interior; "National Leader" (Brasil) do projeto IGCP Archean Geochemistry; "Regional Leader" (Brasil, Uruguai, Paraguai) do projeto CCGM Metamorphic Map of South America; "Continental Leader" (América do Sul) do projeto IGCP-IWGC Igneous and Metamorphic Processes; Pesquisador do projeto IGCP Rapakivi Granites and Related Rocks; Pesquisador do projeto IGCP - Granite Systems and Proterozoic Lithospheric Processes.

Muito ativo, atuou como Pesquisador 1A do CNPq. Publicou perto de uma centena de artigos em revistas nacionais e internacionais, cerca de uma centena de artigos completos e mais de duas centenas de resumos/resumos expandidos em anais de congressos nacionais e internacionais, um livro didático e seis capítulos de livros. Foi o responsável pela integração dos dados geológicos do "Map of Metamorphic Facies in South America 1:5.000.000" publicado pela CPRM em 2004. Também orientou 4 mestrados, 8 doutorados e cerca de 30 iniciações científicas e Trabalhos de Conclusão de Curso na Geologia.

O reconhecimento da importância de suas pesquisas para o meio acadêmico e no avanço do conhecimento nas Geociências se refletem nas inúmeras Premiações e Distinções recebidas ao longo de sua carreira acadêmica, destacando-se: Medalha Martelo de Prata por sua contribuição à Geologia Nacional, concedida em 1972 pela Sociedade Brasileira de Geologia; Medalha Cientista do Ano de Rio Claro, SP, concedida em 1979 pelo Diário de Rio Claro; Membro Titular, Academia de Ciências do Estado de São Paulo (1980); Medalha CNPq por sua contribuição à Ciência Nacional, Conselho de Desenvolvimento Científico e Tecnológico (1981); Diploma por sua contribuição ao desenvolvimento da Geologia do Brasil Central, concedida em 1987 pela Sociedade Brasileira de Geologia; Membro Titular, Academia Brasileira de Ciências (1993); Paraninfo e Homenageado por várias turmas de formandos do curso de Geologia da UNESP-Rio Claro.

Mais do que um geólogo acadêmico pesquisador apaixonado pelos granitos, a comunidade geológica nacional perdeu um eloquente defensor das Geociências que, em suas atividades, suas pesquisas e publicações, em seus discursos e exposições muito contribuiu para o crescimento da Geologia, para a instalação de cursos universitários, para a formação de profissionais da área e, mais diretamente, para a criação, desenvolvimento, fortalecimento e reconhecimento do Curso de Geologia de Rio Claro.

Departamento de Petrologia e Metalogenia Instituto de Geociências e Ciências Exatas UNESP - Universidade Estadual Paulista Júlio de Mesquita Filho 